\title{
Factors Influencing the Research Participation of Adults with Autism
}

\section{Spectrum Disorders}

Kaaren Haas 1,5 khaas@autismspectrum.org.au, Debra Costley 1,5

dcostley@autimspectrum.org.au, Marita Falkmer 2,5 marita.falkmer@curtin.edu.au, Amanda Richdale ${ }^{3,5,}$ a.richdale@latrobe.edu.au, Kate Sofronoff ${ }^{4,5}$ k.sofronoff@psy.uq.edu.au and Torbjörn Falkmer ${ }^{2,5}$ t.falkmer@curtin.edu.au

' Autism Spectrum Australia, 4/3 Aldgate Street and Blacktown Road, Prospect NSW 2I48 Australia

${ }^{2}$ School of Occupational Therapy and Social Work, Faculty of Health Sciences, Curtin University, Bentley WA 6102 Australia

${ }^{3}$ Olga Tennison Autism Research Centre, La Trobe University, Bundoora VIC 3086 Australia

${ }^{4}$ School of Psychology, The University of Queensland, St Lucia QLD 4072 Australia

${ }^{5}$ Cooperative Research Centre for Living with Autism Spectrum Disorders, Level 3, Forestry Building, Long Pocket, The University of Queensland, Brisbane QLD 4072 Australia Corresponding Author

Kaaren Haas, Autism Spectrum Australia, 4/3 Aldgate Street and Blacktown Road, Prospect NSW 2I48 Australia

Telephone +6I 288688508 Fax +6I 298965266 Email khaas@autismspectrum.org.au

\section{Acknowledgements}

The authors acknowledge the contributions of Trevor Clark and Susanna Baldwin, Autism Spectrum Australia to project establishment and design and the contributions of the following to participant recruitment, data collection and data analysis: Lahna Bradley, La Trobe University; Susan Bruck, Autism Spectrum Australia; Heidi Stieglitz Ham, Curtin University; Emma Hyland and Damian Santomauro, The University of Queensland. 
The authors sincerely thank the study participants for their time, opinions and ideas.

\section{Funding}

The authors acknowledge the financial support of the Cooperative Research Centre for Living with Autism Spectrum Disorders (Autism CRC), established and supported under the Australian Government's Cooperative Research Centre's Program.

\section{Declaration of conflicting interests}

The authors declare no potential conflicts of interest with respect to the research, authorship and/or publication of this article.

Word count 7403 words 


\section{Research highlights}

- Identifies the factors influencing the research participation of adults with ASD.

- Factors influencing research participation differ between sub-groups of adults with ASD.

- Factors arising from participant's values act as motivators or deterrents.

- Factors based on convenience act as enablers or inhibitors.

- Choice, flexibility and sensitivity are key to engaging adults with ASD in research. 


\section{Abstract}

The recruitment and retention of adults with autism spectrum disorders (ASD) into research poses particular difficulties; longitudinal studies face additional challenges. To date, factors influencing the participation of adults for ASD research have been unexamined. This article draws on a study conducted in 2014 to identify factors influencing the participation of adults in longitudinal autism research. Quantitative and qualitative data was obtained from 167 participants across Australia in four categories: adults with either high-functioning autism or Asperger syndrome; adults with ASD and an intellectual disability; carers of these adults; and neuro-typical adults. This article includes results for adults with ASD and their carers. Factors influencing participation were found to differ both between and within participant categories. These factors were classified as those arising from a participant's values, which acted as either a motivator or a deterrent; and those based on convenience, which acted as either an enabler or inhibitor. While helping others was a key motivator for all, participants also sought personal benefits, which differed between categories. Belonging to a research community of like-minded people was also a motivator and enabler. The inconvenience of time and travel required was a key inhibitor; insensitivity to an individual's needs and preferences for engaging with the world a key deterrent; maximising choice in all aspects of participant involvement a vital enabler; and the use of financial and other extrinsic rewards was found to be problematic.

\section{Keywords}

altruism, Asperger, Australia, autism, incentive; motivation; research recruitment, research participation 


\section{INTRODUCTION}

Achieving a representative sample is vital to the validity of social research findings, particularly when findings are used as evidence to inform social policies and programs. Adults with autism spectrum disorders (ASD) can be a 'hard-to reach' population for researchers (Beadle-Brown et al., 2012). The unique social-communicative profile associated with the autism spectrum (Howlin, 2005) contributes to the reluctance of some adults with ASD to be involved with new people and experiences or to disclose personal information, affecting their willingness to participate in research. Diagnostic-related assumptions about people with ASD can also lead researchers to develop strategies that exclude or restrict rather than maximise the research participation of people with ASD (Harrington, Foster, Roger, \& Ashburner, 2014). An informed understanding of the factors influencing the likelihood that adults with ASD will participate in research is an essential basis from which researchers can devise and deploy recruitment and retention strategies to optimise participation across the full spectrum of people with ASD.

\section{Why do people participate in research?}

Current research recognises that motivations for participating in research can be defined as either personal or social (e.g., Clark, 2010; Mapstone, Elbourne, \& Roberts, 2007). Hunter, Corocran, Leeder and Phelps (2012, p. 84) conclude that: "while altruism motivates participation in medical research, for many potential participants, the opportunity to benefit directly was the primary, and sometimes the only motive to participate." Mein et al. (2012) observe that rather than being motivated solely by altruism, participants in a longitudinal health study were also motivated by personal benefits including medical information and care received and the sense of loyalty and membership associated with belonging to the study, which the authors term 'conditional altruism'. 
This is consistent with Fry's (2008, p. 44) observation that: “... participant motivation is a multi-dimensional construction..." and "... the relative salience of these types of research participation incentives and barriers varies across participant group, research focus and setting ..." a view shared by others in this field (e.g., Tishler \& Bartholmae, 2002). Fry asserts that: "In spite of this variability ... there is notable consistency in the self-reported reasons for research participation where a number of core themes emerge independently of the type of research in which people are participating" (Fry, 2008, p. 44). He identifies these core themes as factors that can motivate participation (e.g., information access, financial gain, altruism, expected therapeutic benefit) and factors that can discourage participation (e.g., inconvenience, risk, discomfort).

Nicholson, Coyler and Cooper (2013) group the factors influencing participant recruitment in intellectual disability research into seven themes: participant attributes, research process, researcher's standing and style as perceived by the participant, impact of participant's previous experience with research, attitudes of participant's family and carer(s), use of an 'active' recruitment approach and motivators. Similarly, Robinson, Dennison, Wayman, Pronovost and Needham (2007) compare 368 retention strategies from 21 varying health-related studies and classify these retention strategies into 12 themes: community involvement, study identity, study personnel, study description, contact and scheduling methods, reminders, visit characteristics, study's benefits, financial incentives, reimbursement, non-financial incentives and special tracking methods. Noting this diversity of themes, three systematic reviews of recruitment and/or retention strategies (Beadle-Brown, 2012; Mapstone et al., 2007; Robinson et al., 2007) each recommend that to optimise participant retention, researchers should combine a greater number of retention strategies from across a wider variety of such themes. 
Individual personality traits could also influence participation in research. Marcus and Schütz (2005) observe that research volunteers were more extraverted, more open to experience and more narcissistic than non-volunteers.

An additional factor is the participant-researcher relationship. Beadle-Brown et al. (2012) conclude that researchers' conventional views about what data should look like, assumptions about the efficacy or validity of including particular types of people and stereotyped views about people outside the 'mainstream' can significantly influence research design and result in excluding certain groups of people.

Table 1 summarises commonly-identified motivators and barriers to participation in longitudinal research projects, as found in the literature.

\section{Table 1 here}

\section{Recruitment and retention of participants with an intellectual disability}

Studies exploring how to improve the research participation of people with an intellectual disability provide useful insights for autism research. Stigma engendered by negative public attitudes to disability and the resultant low self-esteem and reluctance of people living with disability to identify with a particular condition (such as autism) have been found likely to discourage research participation for people with an intellectual disability (Thompson \& Phillips, 2007). Approaches found to produce higher participation rates in intellectual disability research include enabling investigators to have direct access to participants, using non-invasive data collection methods and requiring consent from substitute decision makers only (Cleaver, Ouelette-Kuntz \& Sakar, 2010). Lennox et al. (2005) concluded that recruitment for intellectual disability research was best achieved through direct contact from a service provider staff member to the adult with an intellectual disability and their caregivers. Gatekeepers of people with an intellectual disability, such as doctors, care managers, support workers, carers and parents can potentially act as a barrier when these 
third parties either select potential participants or seek to 'protect' them (Beadle-Brown et al., 2012).

These findings support those of Ouellette-Kuntz, Lunsky, Lysaght, Marton and Saaltink (2013) that recruitment of participants with an intellectual disability was most successful where: there was an established relationship between the participant and a research team member; and when a third party assisted recruitment, it was made clear to the participant, their family and carers which person(s) and which organisation was conducting the research; and was least successful in those cases where the study relied on a third party for recruitment; there was a considerable time lag between the participant's expression of interest and their engagement in the research; and data collection relied on face-to-face interviews. They also found that participation rates in intellectual/developmental disability research were positively influenced by financial incentives, though the most effective type of financial incentive was unclear.

\section{Engaging adults with ASD in longitudinal research}

In the systematic review by Magiati, Tay and Howlin (2014) of longitudinal studies investigating the cognitive, language and social behavioural outcomes for adults with ASD, each of the 25 studies had initially recruited the participants as children and thus provided no insights into techniques for recruiting adults with ASD. Similarly, of 18 peer-reviewed articles identified reporting on results from longitudinal studies of adults with ASD, 15 articles drew on data from participants initially recruited in childhood. The remaining three studies had recruited adult participants, however none reported on the effectiveness of the recruitment approaches used or factors influencing participation (Cederlund, Hagberg, Billstedt, I. Gillberg, \& C. Gillberg, 2008; Gerber et al., 2011; Madriaga, 2010).

Two recent studies involving adults with ASD comment on engaging participants. Balfe and Tantam (2010) note that techniques which could be effective in recruiting younger 
children are not necessarily suitable for the recruitment of adults and school leavers as “... adults and older adolescents are not 'captive populations' in the same way that children are." (Balfe \& Tantam, 2010, p. 2). MacLeod, Lewis and Robertson (2014) describe using participatory research methodology to overcome barriers to participation faced by higher education students with ASD in dealing with a neuro-typical world and conclude that this approach was successful. Participants had a keen interest in autism research, demonstrated commitment to the project, viewed themselves as "potential agents of change" and expressed the wish to improve the understanding of autism and help others (Macleod et al., 2014, p. 47).

These limited insights from the literature indicate that the factors influencing participation in research for adults with ASD are yet to be identified or examined in any depth. The current study addresses this gap by reporting the results for adults with ASD and their carers from a larger study undertaken in 2014 to identify factors that influence the participation of adults in longitudinal autism research (Haas, Costley, M. Falkmer, Richdale, Sofronoff, \& T. Falkmer, $2014 *$ to be anonymised for journal submission).

\section{MATERIALS AND METHODS}

\section{Participants}

Researchers recruited 167 participants for the study, mainly from four major Australian cities (Sydney, Melbourne, Brisbane and Perth), with a smaller proportion from regional areas. As shown in Table 2, participants were recruited in four categories: adults diagnosed with high functioning autism/Asperger's Syndrome (HFA/AS); adults diagnosed with an ASD and an intellectual disability (ASD+ID); carers of ASD+ID adults (Carers); and neuro-typical adults (NT). No participants withdrew from the study. This article reports on findings for those participants with ASD and their Carers. 


\section{Table 2 here}

\section{Materials}

In focus groups and interviews, researchers collected data via a card sort exercise and a questionnaire completed by each participant, which yielded quantitative and qualitative data on participants' attitudes to research, preferences for modes of participating in research and the likelihood of certain factors motivating, enabling or inhibiting participants' involvement in autism research. The topics canvassed and questions used in the card sort exercise and questionnaire were generated from the commonly identified incentives and disincentives for participation in longitudinal research listed in Table 1. An online survey incorporated the focus group questionnaire and card sort exercise, with prompts for additional open-ended comments. The card sort exercise, questionnaire and discussion points are available in Haas et al., (2014)* to be anonymised for journal submission.

\section{Procedure}

Ethics approval for the study was obtained from La Trobe University (\#14-005), Autism Spectrum Australia (\#1141), The University of Queensland (\#201400500) and Curtin University (\#HR73/2014).

\section{Recruitment}

Various methods were used to recruit participants including posting on social media (Twitter, Facebook) and websites via autism service providers, autism community networks and autism support groups and autism research groups, centres and networks. Flyers were sent to be displayed in venues of autism-related organisations and to community, university-based disability support services, autism-related social groups, psychologists specialising in autismrelated services and carer networks. Potential participants were also approached personally and through social media by individuals already recruited to the study who were active, wellconnected and well-known as advocates in the autism/Asperger's community. Researchers 
gave presentations about the study to autism and disability support groups. Information about the study was also distributed to individuals on research participant registries held by study partner organisations. In some cases, information was distributed by personal contacts to participants in previous autism-related studies.

Each participant was screened for study inclusion based on place of residence (Australia only); age (18+ years only); self- or proxy-reported diagnosis of ASD (and intellectual disability as applicable); and carer responsibilities.

A completed consent form was required from all participants prior to participation. Carer/guardian written consent was also required for participants with an intellectual disability and from those carers who accompanied other ASD participants to a focus group or interview.

\section{Focus groups and interviews}

Seventeen focus groups and 17 interviews were conducted from May to July 2014 with a total of 129 participants. The focus groups involved 110 participants and ranged in size from three to 12 participants, with a median size of six. Interviews, either individual or small group, were conducted with 21 participants where the participant indicated that they were unable to or did not wish to attend a focus group or the researcher judged that based on the communication style and cognitive abilities of the participant, an interview would be more effective than a focus group. After completing the card sort exercise and questionnaire a discussion was facilitated by a researcher, based on participants' responses to these activities. This yielded qualitative data on participants' attitudes, reasoning, motivations and preferences about factors likely to influence their participation in autism research. All focus group and interview participants were provided with a $\$ 20$ shopping voucher at the end of the session. Participants who travelled more than $20 \mathrm{~km}$ to attend a focus group or interview received partial reimbursement for travel costs. 


\section{Online survey}

The study incorporated an online survey, based on feedback from participants during the initial recruitment process that limiting data collection to focus groups and interviews was potentially only appealing to those willing to engage in social interactions. Over a two-week period in June 2014 a total of 38 participants across all categories completed the online survey.

\section{Data analysis}

Quantitative data collected via the card sort exercise, questionnaire and online survey were collated and tabulated, and a frequency analysis produced for each question, cross tabulated by participant category and mode of participation. Participants' commentaries in focus groups, interviews and extended responses in online survey were transcribed from audio recordings and the online survey data and coded for thematic analysis.

\section{RESULTS}

The results indicate that some motivators, inhibitors and enablers of participation were common to all participants while other motivators, inhibitors and enablers differed markedly between different types of participants. Some factors identified as motivators for certain participants were found to be either inhibitors or enablers for others.

\section{Common motivators}

\section{A brighter future}

Most participants were primarily motivated to engage with autism research as a way to help improve the lives of people with ASD. Eighty-five percent of HFA/AS participants, $86 \%$ of ASD+ID participants and 94\% of Carers said they would be more likely to participate if the research was likely to benefit other people, especially those with ASD. In supporting autism research, participants voiced strong support for research focused on producing practical programs to improve opportunities for adults with ASD to engage in all aspects of life in 
meaningful and rewarding ways, to be adequately recognised for their abilities and contributions, and to enable greater acceptance and understanding of them by the wider community.

While helping others was found to be a key motivator, $59 \%$ of HFA participants, $60 \%$ of ASD+ID participants and 59\% of Carers agreed that if they were going to take part in a research project, they wanted to know that they would personally benefit from the research. What participants considered a 'personal benefit' differed between participant categories. For adults with ASD, 'personal benefit' was viewed through the lens of their individual preferences and needs and their desire for improved opportunities to engage in all aspects of life in meaningful and rewarding ways. HFA/AS participants were most keen to have their voices heard and understood, while some also sought opportunities for social engagement, particularly with others similar to them. For most ASD+ID participants, receiving acceptance was a key motivator. Some also sought recognition and appreciated extrinsic rewards, such as gifts and cards. Carers of adults with ASD interpreted 'personal benefit' in terms of benefit to their child rather than to themselves.

Personal learning and development was a notable 'personal' benefit valued by participants. Seventy-four percent of HFA/AS participants and $71 \%$ of Carers said they would be more likely to participate if the research would help them learn more about autism and/or themselves. HFA/AS participants commented that information they received via group discussions, project communications and interactions with the project team would assist their personal learning and development. Similarly, Carers commented that the opportunity for their adult child to learn more about themselves and autism would benefit their child's personal development and self-awareness, including 33\% of Carers who expressed an interest in their child working 'behind the scenes' to assist with the administration and conduct of a research project. Some HFA/AS participants (48\%) were also keen for any opportunity to 
work 'behind the scenes': those in focus groups (55\%) showed much more interest than those responding via online survey $(11 \%)$.

The desire of participants with ASD to support research was tempered by some (26\%) who were suspicious about the motives behind large-scale research projects.

\section{Belonging in a caring community}

Participants indicated a desire to draw comfort, a sense of worth and inspiration from belonging to a research project community. For example, $66 \%$ of HFA/AS participants, $60 \%$ of ASD+ID participants and $71 \%$ of Carers indicated they would use a project website where they could ask questions, give feedback and engage in online discussions with the research team and other study participants. Common reasons that participants valued such a website were the flexibility to engage in an online community as it suits the individual, the opportunity to form and engage in relationships online, the facility to exchange helpful information, and the reassuring support of a community of people with similar interests. Project communication was also found to be an important part of engendering this sense of belonging.

\section{Being informed and updated}

Most participants were keen to receive project communications, including newsletters (67\%), website $(71 \%)$, and outcomes reports $(82 \%)$. Participants indicated they valued receiving ongoing and updated information about the project and its progress, about how their input had contributed to outcomes and being able to see and compare others' responses and contributions.

\section{Common inhibitors}

Travel and time

Some HFA/AS participants (34\%) and Carers (41\%) considered any significant amount of travel (over 50km round trip) would be a barrier, citing cost, inconvenience and anxiety 
associated with travel. However, $76 \%$ of HFA/AS participants and $88 \%$ of Carers said reimbursement for travel costs would encourage their participation.

Carers (65\%) and ASD+ID participants (60\%) were concerned to have adequate time to complete surveys. Boredom and shorter concentration were also issues for ASD+ID participants when completing surveys. Comments from ASD+ID participants and Carers highlighted that such tasks need to be broken into smaller sections to be completed over a longer time period.

(In) sensitivity

Some HFA/AS participants advocated that researchers use methods, notably in data collection, that are sensitive to HFA/AS participants' particular and individual cognitive styles so that these participants can make meaningful contributions. This included providing opportunities for participants to clarify the meaning of questions or provide explanations to researchers about the participant's responses to questions. They also suggested researchers carefully choose venues for activities to ensure enjoyable and productive experiences for HFA/AS participants. Suggestions included convenient locations, quiet acoustics, a private venue, and a relaxed, informal setting. Some HFA/AS participants commented that to support their difficulties with executive functioning, they would need reminders to undertake activities. In conducting this study it was also found that visual aids assisted in project communication and data collection with ASD+ID participants. Some HFA and ASD+ID participants requested that a carer or companion accompany them in a focus group or interview for reassurance and in some cases, for assistance with concepts and communication.

\section{Mental and physical health}

A notable proportion of ASD+ID participants (47\%), HFA/AS participants (38\%) and Carers (29\%) said their mental health might be a barrier to participation or were unsure if it might 
be. Some HFA/AS participants at focus groups (33\%) and ASD+ID participants (27\%) said their physical health might be a barrier but this was not a concern for either Carers or HFA/AS participants in the online survey, though some (22\% and $18 \%$ respectively) were unsure about this.

\section{Common enablers}

Choice

Maximising choice for all aspects of project involvement was seen as a vital enabler of participation, because it allows for the breadth and idiosyncratic nature of the personal preferences and needs of individuals across the autism spectrum. Most HFA/AS participants (76\%), ASD+ID participants (79\%) and Carers (82\%) said a choice of how to participate would make them more likely to participate. HFA/AS participants expressed that they did not want to be "boxed in" to any pre-conceived notions of what might appeal to them or not. They commonly expressed that they would appreciate the choice to accept or decline anything offered to them, whether extrinsic rewards (e.g., gift, voucher, cash), project communications (e.g., newsletters, reports, reminders) or event invitations. HFA/AS participants suggested being given an option as to whether they wished to receive any particular communication, their preferred format for each communication (e.g., digital or print), and the option to receive a summary or a plain language version of any report or a face-to-face session explaining the project outcomes. The flexibility of cash payments (as reward for participation) was generally preferred to receiving a voucher.

\section{Access to researchers}

Most HFA/AS participants (61\%) and Carers (70\%) and some ASD+ID participants (47\%) said they would be more likely to participate if they could contact the research team directly at any time by telephone or email. Access to researchers was either a common motivator or enabler for reasons that differed between participant categories. For HFA/AS participants, a 
key reason was the opportunity to either clarify a survey question or to explain the participant's response to a survey question. Carers expressed two key reasons: for many, it would enable them to make practical arrangements with the researchers to facilitate their child's participation in the research study, while other Carers and some HFAS/AS participants were keen to be able to readily contact researchers for information or advice concerning autism related issues.

\section{Differentiators}

\section{Extrinsic rewards}

While participants welcomed any acknowledgement of the time and effort that they contribute, the results show that using financial and other extrinsic rewards is likely to be problematic as a means of encouraging people to participate in autism research. For some these rewards were an enabler of participation, for others they were an inhibitor.

Within the HFA/AS participants, 53\% said they would be more likely to participate if they received cash payments or vouchers as thanks for their participation, while $34 \%$ indicated that such rewards would make no difference to their likelihood to participate. HFA/AS participants generally considered extrinsic rewards to be less meaningful and relevant as motivators of their participation than the intrinsic benefits they might gain, and for those willing to accept extrinsic rewards, such incentives were not the key motivator of their participation. Of those HFA/AS participants who said they would be less likely to participate if they received cash payments or vouchers, many expressed distaste for or disapproval of such incentives.

Over half of HFA/AS participants (53\%) said receiving a birthday card from the research team would make no difference to their participation, while $27 \%$ indicated it would discourage their participation. Similarly, $43 \%$ said receiving a small gift, three times a year would make no difference and $19 \%$ said it would discourage their participation. Support for 
receiving a 'tell-a-friend' reward for enlisting others into the study was lower: only $31 \%$ said it would encourage their participation, $50 \%$ said it would make no difference and for $19 \%$ it would discourage their participation. Instead, HFA/AS participants expressed that extrinsic rewards were valued as recompense for expenses such as time, travel and child-minding.

Most ASD+ID participants were happy to receive extrinsic rewards. About half of ASD+ID participants said receiving acknowledgment and recognition, such as an article about them in the project newsletter $(53 \%)$ or a birthday card $(47 \%)$ would encourage their participation. Many said receiving vouchers (67\%), or cash (67\%) would encourage their participation. Gifts were somewhat problematic: $43 \%$ of ASD+ID participants responded that gifts would encourage their participation, however an equal proportion (43\%) said it would make no difference, with the remaining $14 \%$ indicating that gifts would discourage their participation.

Consistent with their primary focus on others and their children, Carers showed little or no interest in receiving any exposure or recognition for themselves.

\section{Social interaction}

Preferences about social interaction produced divergent responses about activities requiring participants to be with other people.

Some participants with ASD, including those with HFA/AS and those with an intellectual disability, expressed that they did not enjoy or were fearful of social interaction, or were concerned about mixing in large groups and preferred engaging within smaller groups. For others, the opportunity for social interaction, particularly with others similar to themselves, was a prime motivator and their preferred mode for participation in research. This divergence was consistent across both HFA/AS and ASD+ID participants.

Most HFA/AS participants at focus groups highly valued the opportunity for interaction with others who were similar to them and enthusiastically engaged in these 
interactions. Most said meeting and sharing experiences with others at events such as discussion groups $(72 \%)$ or drinks receptions $(59 \%)$ would increase the likelihood of their participation. Of prime importance for these participants was the lively and free exchange of views, in an environment of mutual understanding and acceptance of differences where much that is particular to them does not need any explanation. This sharing of opinion and experiences was valued for the supportive contact, learning and self-development it affords.

Others expressed a preference for face-to-face communication because it lessens the chance for ambiguity and misunderstandings and prompts them for contributions. Some HFA/AS participants also viewed such events as opportunities to meet researchers, either to exchange views, learn more about autism or query the researcher's approach to autism research. For other HFA/AS participants at focus groups, the social aspect was either less important or not relevant to them. Instead, they valued the opportunity to contribute and exchange opinions around a specified topic of interest to them while undertaking a purposeful task in a structured format (and this in part ameliorated their distaste for or anxiety about the social setting).

A considerable proportion HFA/AS participants responding via online survey said meeting and sharing experiences with others at events such as a discussion group (44\%) or a drinks reception (33\%) would decrease the likelihood of their participation.

ASD+ID participants also divided into those who would enjoy activities with social interaction, particularly interactions with others similar to them, and those who did not seek or enjoy social interaction. Sixty per cent said meeting and sharing experiences with others at a discussion group would increase the likelihood of their participation; $40 \%$ said it would discourage their participation. Fewer (43\%) were enthusiastic about attending a drink reception; an additional 33\% were unsure about such an event. 
Most Carers said meeting and sharing experiences with others at events such as discussion groups $(53 \%)$ or drinks receptions $(71 \%)$ would increase the likelihood of their participation. Some were reticent to participate in a forum where negative aspects of caring for an ASD+ID child might dominate the discussion.

\section{Preferred modes of data collection}

Preferences about modes of participation also produced divergent responses between and within the participant categories (Table 3).

Most ASD+ID participants said they would not enjoy telephone and paper surveys or were unsure about them. Carers commented that paper or online surveys would be more manageable and effective for their child than telephone surveys or interviews. Internet or telephone access was not identified as a significant barrier to participation for HFA/AS or ASD+ID participants, but a notable minority of Carers did not have regular access to either the internet $(18 \%)$ or a telephone $(12 \%)$.

Table 3 here

Participation by a friend or family member

Most HFA/AS participants perceived participation in research as an individual, personal engagement. Participation by a friend or family member was likely to encourage $31 \%$ of HFA/AS participants to take part in research and $60 \%$ of ASD+ID participants. The full support of carers of ASD+ID participants was in almost all cases essential to organise, enable and facilitate the participant's involvement and expression of their views in this study.

\section{Recruitment strategies}

A 'broad brush' method was least effective in recruiting for each of the participant categories; it was more effective to tailor the networks, methods, channels and messages to appeal to each specific participant category. 
Effective methods of recruiting HFA/AS participants included: via social media of autism support networks, support groups and service providers; assistance from active, highprofile and well-connected advocates in the HFA/AS community (as this provided credentialed and trusted access to participants) and snowballing, by encouraging neurotypical participants already recruited to the study to enlist relatives and friends with ASD to also join.

ASD+ID participants were the most challenging to recruit. It was essential to first recruit carers as co-participants, because carers generally acted as the 'gatekeeper' and conduit for communications and consent.

Carers were most effectively reached through disability networks rather than via the autism community. While a small proportion were recruited via social media, most Carers were found with the assistance of disability carer network organisations and disability service providers who enabled credentialed and trusted access.

\section{DISCUSSION}

\section{Common factors}

This study adds to the existing knowledge about recruitment and retention for research by identifying a number of factors influencing research participation that are particularly relevant to the lived experience of adults with ASD. For example, factors found to be vital enablers of research participation by people with ASD (and inhibitors when absent) were the sensitivity shown to each individual's personal needs and preferences for engaging with the world and others; and related to this, maximising the choices available for participants across all aspects of their involvement in the research. Broadly, the desire for maximum choice and sensitivity to individual needs reflects the self-focus of people with ASD (Baron-Cohen, 2000) together with the diversity of cognitive functioning and skills, behaviours, lifestyles 
and personal preferences that is observed across the autism spectrum (Mazefsky \& White, 2014).

Some factors we found influencing the research participation of adults with ASD are similar to those identified in the literature for neuro-typical people and people with an intellectual disability). The motivators of participation were found to be both social and personal in nature (as reported by Barton et al., 2012; Clark, 2010; Hunter et al., 2012; Kirkland et al., 2009; Mapstone et al., 2007; Mein et al. 2012). Travel and time were common inhibitors to participation (e.g., Barton et al., 2012; Beadle-Brown et al., 2012; Bonk, 2010; Brodaty et al., 2013; Marcantonio et al., 2008; Nicholson et al., 2012) while information access (Barton et al., 2012; Hunter et al., 2012; Leonard et al., 2003; Mein et al., 2012) and belonging to a research community (Mein et al., 2012; Robinson et al., 2007) were enablers of participation.

The results also indicate that, in contrast with the results of previous studies involving neuro-typical participants only (Leonard et al., 2003; Marcantonio et al., 2008; Tishler \& Bartholomae 2002), offering extrinsic rewards as an incentive for participation could be problematic in research involving people with ASD, because such rewards act as an enabler for some and an inhibitor for others. Again this is indicative of diversity of presentations encompassed within the autism spectrum (Mazefsky \& White, 2014). It also reflects a sentiment specific to the HFA/AS participants rejecting tokenism and paternalism.

\section{Differentiating factors}

While there were general findings applicable to all participants with ASD and their carers, the responses of each participant category displayed a number of themes unique to that category.

HFA/AS participants wanted to be heard and understood as equal and valued partners in research in order to both improve community understanding of ASD and to participate in the wider community. They rejected tokenism and were generally not interested in extrinsic 
rewards for research participation; rather they wanted respect for themselves and their point of view. Furthermore some individuals wanted to be key decision makers in research, based on their concerns that their views are commonly misrepresented, misinterpreted and misused by the wider community, especially neuro-typical researchers.

For ASD+ID participants, belonging and acceptance, wanting to know 'what was happening' and what others were doing, especially people known to them were key motivators for research participation. Involvement in research required flexibility in the mode of participation, relationships of trust with researchers, the capacity to fit the research activities into the participant's normal daily routine, and a sense of security, safety and calm in the research environment. Many ASD+ID participants expressed a liking for extrinsic rewards and any public recognition of their research participation provided a muchappreciated boost to their self-esteem and public profile.

The responses of Carers were characterised by a balance of altruism and pragmatism. The key focus of Carers was the development of practical knowledge and solutions about ASD to improve their child's well-being and life choices. Carers were not unconcerned about obtaining 'personal' benefits, but these were interpreted from the perspective of their carer role. Thus, they were vitally concerned to protect their child and their child's privacy, but were unconcerned about disclosure of their own personal information. Carer's desire, willingness and capacity to contribute were balanced by their need to manage the daily practicalities of caring for an adult with a disability. A key concern was how they would facilitate their child's participation in research, such as organising and funding travel, communicating with the research team and finding appropriate modes of participation for their child. 


\section{Differentiating between motivators, deterrents, enablers and inhibitors}

Previous studies of factors influencing research participation have commonly divided factors into two simple categories, being those with either a positive or negative impact ( e.g. Mapstone et al., 2007; Fry 2008). However, our analysis indicated that our understanding of participant behaviour can be furthered by distinguishing between those factors arising from participant values which act as either a motivator or a deterrent; and those factors based on convenience, which act as either enablers or inhibitors. Thus, value-based outcomes that participants with ASD sought to obtain such as altruism, access to information and sense of community were observed as motivators of their research participation. Tokenism and insensitivity to an individual's needs were deterrents to research participation, being outcomes that did not align with participants' expressed values. Convenience based factors that influenced the research participation of people with ASD included maximising choice, which acted as an enabler (as distinct from a motivator) and the cost and time of travel, which acted as an inhibitor.

\section{Limitations}

While a range of methods was used to engage as broad a spectrum of participants as possible, the reach of the study is limited by the effectiveness of the recruitment communications, the time period for recruitment, particularly for the online survey and the modes of participation offered. We did not examine reasons for non-participation. Although we sought to gather data from a representative sample of the population based on age and gender, we have not examined the impact of any socio-demographic factors on factors influencing participation in autism research.

\section{CONCLUSIONS}

The results indicate that the factors that either motivate, inhibit, deter, and enable the research participation of adults with ASD differ markedly between those with high-functioning autism 
or Asperger syndrome, those with an intellectual disability; and their Carers, and also between individuals within these categories. Thus, a 'one size fits-all' approach will not be effective in optimising the research participation of adults with ASD. Instead, choice, flexibility and sensitivity are likely to be key elements in a successful strategy to engage adults with ASD in research.

\section{REFERENCES}

Balfe, M. \& Tantam, D. (2010). A descriptive social and health profile of a community sample of adults and adolescents with Asperger syndrome. BMC Research Notes, 3(300), 1-7.

Baron-Cohen, S. (2000). Theory of mind and autism: A review. In L. Masters Glidden (Ed.), International Review of Research in Mental Retardation (Vol. 23, pp. 169-184): Academic Press.

Barton, C. A., May, C., Mészáros, D., Matheson, M. C., Jenkins, M., Giles, G., . . . Abramson, M. J. (2012). Reasons for ongoing participation in a longitudinal cohort study. Australian \& New Zealand Journal of Public Health, 36(4), 397-398.

Mazefsky, C. A. \& White, S. W. (2014). Adults With Autism. In F. R. Volkmar, R. Paul, S. J. Rogers, \& K. A. Pelphrey (Eds.), Handbook of Autism and Pervasive Developmental Disorders, (Fourth ed.): John Wiley \& Sons, Inc.

Beadle-Brown, J., Ryan, S., Windle, K., Holder, J., Turnpenny, A., Smith, N., Richardson, L. \& Whelton, B. (2012). Engagement of people with long-term conditions in health and social care research: Barriers and facilitators to capturing the views of seldom-heard populations: Policy Research Unit in the Quality and Outcomes of person-centred care. 
Bell, K. (2013). Participants' motivations and co-construction of the qualitative research process. Qualitative Social Work, 12(4), 523-539.

Bonk, J. (2010). A road map for the recruitment and retention of older adult participants for longitudinal studies. Journal of the American Geriatrics Society, 58(s2), S303-S307.

Brodaty, H., Gibson, L. H., Waine, M. L., Shell, A. M., Lilian, R., \& Pond, C. D. (2013). Research in general practice: a survey of incentives and disincentives for research participation. Mental Health in Family Medicine, 10(3), 163-173.

Cederlund, M., Hagberg, B., Billstedt, E., Gillberg, I. C., \& Gillberg, C. (2008). Asperger syndrome and autism: a comparative longitudinal follow-up study more than 5 years after original diagnosis. Journal of Autism and Developmental Disorders, 38(1), 7285.

Clark, T. O. M. (2010). On 'being researched': why do people engage with qualitative research? Qualitative Research, 10(4), 399-419.

Cleaver, S., Ouellette-Kuntz, H., \& Sakar, A. (2010). Participation in intellectual disability research: a review of 20 years of studies. Journal of Intellectual Disability Research, 54(3), 187-193.

Fry, C. L. (2008). Research Participation and Internal Normativity: Understanding Why People Participate. The American Journal of Bioethics, 8(10), 43-44.

Gerber, F., Bessero, S., Robbiani, B., Courvoisier, D.S., Baud, M.A., Traoré, M-C., Blanco, P., Giroud, M. \& Carminati, G.G. (2011). Comparing residential programmes for adults with autism spectrum disorders and intellectual disability: outcomes of challenging behaviour and quality of life. Journal of Intellectual Disability Research, 55(9), 918-932.

Haas, K., Costley, D., Falkmer, M., Sofronoff, K., Richdale, A. \& Falkmer, T (2014). Optimising the recruitment and retention of adults for longitudinal autism research: a 
mixed methods study. Brisbane: Cooperative Research Centre for Living with Autism Spectrum Disorders, http://www.autismcrc.com.au/reports. * to be anonymised for journal submission

Harrington, C., Foster, M., Rodger, S., \& Ashburner, J. (2014). Engaging young people with Autism Spectrum Disorder in research interviews. British Journal of Learning Disabilities, 42(2), 153-161.

Howlin, P. (2005). Outcomes in autism spectrum disorders. In F. R. Volkmar, R. Paul, A. Klin, \& D. Cohen (Eds.), Handbook of autism and pervasive developmental disorders (3rd ed., Vol. 1: Diagnosis, development, neurobiology, and behavior, pp. 201-220). Hunter, J., Corcoran, K., Leeder, S., \& Phelps, K. (2012). Appealing to Altruism is Not Enough: Motivators for Participating in Health Services Research. Journal of Empirical Research on Human Research Ethics, 7(3), 84-90.

Kirkland, S. A., Raina, P. S., Wolfson, C., Strople, G., Kits, O., Dukeshire, S., Angus, L., Szala-Meneok, K., Uniat, J., Kesjavarz, H., Furlini, L. \& Pelletier, A. (2009). Exploring the Acceptability and Feasibility of Conducting a Large Longitudinal Population-Based Study in Canada. Canadian Journal of Aging, 28(3), 231-242.

Lennox, N., Taylor, M., Rey-Conde, T., Bain, C., Purdie, D. M., \& Boyle, F. (2005). Beating the barriers: recruitment of people with intellectual disability to participate in research. Journal of Intellectual Disability Research: JIDR, 49(Pt 4), 296-305.

Leonard, N. R., Lester, P., Rotheram-Borus, M. J., Mattes, K., Gwadz, M., \& Ferns, B. (2003). Successful recruitment and retention of participants in longitudinal behavioural research. AIDS Education and Prevention, 15(3), 269.

MacLeod, A. G., Lewis, A., \& Robertson, C. (2014). 'CHARLIE: PLEASE RESPOND!' Using a participatory methodology with individuals on the autism spectrum. International Journal of Research and Method in Education, 37(4), 407-420. 
Madriaga, M. (2010). 'I avoid pubs and the student union like the plague': Students with Asperger Syndrome and their negotiation of university spaces. Children's Geographies, 8(1), 39-50.

Magiati, I., Tay, X. W., \& Howlin, P. (2014). Cognitive, language, social and behavioural outcomes in adults with autism spectrum disorders: A systematic review of longitudinal follow-up studies in adulthood. Clinical Psychology Review, 34(1), 7386.

Mapstone, J., Elbourne, D., \& Roberts, I. (2007). Strategies to improve recruitment to research studies. Cochrane Database Syst Rev, 2.

Marcantonio, E. R., Aneja, J., Jones, R. N., Alsop, D. C., Fong, T. G., Crosby, G. J., Culley, D.J., Cupples, A. \& Inouye, S. K. (2008). Maximizing clinical research participation in vulnerable older persons: identification of barriers and motivators. Journal of the American Geriatrics Society, 56(8), 1522-1527.

Marcus, B., \& Schütz, A. (2005). Who Are the People Reluctant to Participate in Research? Personality Correlates of Four Different Types of Nonresponse as Inferred from Selfand Observer Ratings. Journal of Personality, 73(4), 959-984.

Mein, G., Seale, C., Rice, H., Johal, S., Ashcroft, R. E., Ellison, G., \& Tinker, A. (2012). Altruism and participation in longitudinal health research? Insights from the Whitehall II Study. Social Science \& Medicine, 75(12), 2345-2352.

Nicholson, L., Colyer, M., \& Cooper, S. A. (2013). Recruitment to intellectual disability research: a qualitative study. Journal of Intellectual Disability Research, 57(7), 647 656.

Ouellette-Kuntz, H., Lunsky, Y., Lysaght, R., Martin, L., \& Saaltink, R. (2013). Partnering for Research in the Field of Intellectual/Developmental Disabilities--Lessons For Participant Recruitment. Journal on Developmental Disabilities, 19(2), 25 -35. 
Robinson, K. A., Dennison, C. R., Wayman, D. M., Pronovost, P. J., \& Needham, D. M. (2007). Systematic review identifies number of strategies important for retaining study participants. Journal of Clinical Epidemiology, 60(8), 757-e751.

Thompson, S., \& Phillips, D. (2007). Reaching and engaging hard-to-reach populations with a high proportion of nonassociative members. Qualitative Health Research, 17(9), 1292-1303. Qualitative Health Research, 17, 1292 -1303.

Tishler, C. L., \& Bartholomae, S. (2002). The Recruitment of Normal Healthy Volunteers: A Review of the Literature on the Use of Financial Incentives. J Clin Pharmacol, 42, 365-375. 


\section{Table I: Commonly-identified incentives and disincentives for participation in longitudinal research}

INCENTIVES

Intrinsic incentives

Desire to help others and contribute to valued research (Bell, 2013; Brodaty et al., 2013; Marcantonio et al., 2008)

Gain information and personal insight gained about self (Hunter et al., 2012, Mein et al., 2012)

Voice and share experiences and concerns (Bell, 20I3)

Participation as therapy (Bell, 2013)

Belonging to a community (Mein et al., 2012, Robinson et al., 2007)

Extrinsic incentives

Monetary payments and gifts (Leonard et al., 2003; Marcantonio et al., 2008;

Tishler \& Bartholomae 2002)

Tell-a-friend rewards (Bonk, 20I0)

Birthday cards (Bonk, 20I0; Leonard et al., 2003)

Annual drinks reception to report results (Bonk, 20l0)

Procedural incentives

Reminders (Leonard et al., 2003; Robinson et al., 2007)

Choice of how and when to participate (Marcantonio, et al.; 2008, Mein et al., 20II)

Manner and perceived credibility of researchers (Nicholson et al., 2012;

Robinson et al., 2007)

Project updates/newsletters (Leonard et al., 2003)

\section{DISINCENTIVES}

Intrinsic disincentives

Lack of faith in researcher (Marcantonio, et al., 2008)

Suspicion or anxiety about the study (Bonk, 2010; Lennox et al., 2005;

Nicholson et al., 2012)

Extrinsic disincentives

Lack of time (Brodaty et al., 2013; Nicholson et al., 20I2)

Travel (Beadle-Brown et al., 2012; Marcantonio et al., 2008)

Time required ( Bonk, 20l0)

Procedural disincentives

Excessive paperwork (Brodaty, et al., 2013)

Inadequate explanation of research (Beadle-Brown et al., 2012; Brodaty et al., 2013, Nicholson et al., 2013, Robinson et al., 2007)

Concerns re privacy of personal data (Kirkland et al., 2009) 
Table 2: Total number of participants, by participant category, gender and age

\begin{tabular}{lccccccc}
\hline CATEGORY & MALE & FEMALE & $\begin{array}{c}\text { GENDER } \\
\text { UNSPECIFIED }\end{array}$ & TRANSGENDER & $\begin{array}{c}\text { TOTAL } \\
\text { PARTICIPANTS }\end{array}$ & $\begin{array}{c}\text { AGE } \\
\text { RANGE } \\
\text { (years) }\end{array}$ & $\begin{array}{c}\text { MEAN } \\
\text { AGE } \\
\text { (years) }\end{array}$ \\
\hline HFA/AS & 39 & 23 & 0 & 0 & 62 & $18-78$ & 36 \\
\hline ASD+ID & 13 & 2 & 0 & 0 & 15 & $18-58$ & 25 \\
\hline CARERS & 3 & 12 & 2 & 0 & 17 & $25-63$ & 44 \\
\hline NT & 22 & 35 & 15 & 1 & 73 & $19-62$ & 32 \\
\hline TOTAL & 77 & 72 & 17 & 1 & 167 & $18-78$ & 34 \\
\hline
\end{tabular}


Table 3: How do you feel about this way of collecting information from you?

\begin{tabular}{lccc}
\hline \multicolumn{1}{l}{ WOULD ENJOY } & NOT SURE & WOULD NOT ENJOY \\
\hline ASD+ID participants & & & \\
\hline Face-to-face interview & $46.7 \%$ & $26.7 \%$ & $26.7 \%$ \\
\hline Focus group & $46.7 \%$ & $26.7 \%$ & $26.7 \%$ \\
\hline Online survey & $46.7 \%$ & $26.7 \%$ & $26.7 \%$ \\
\hline Telephone interview & $40.0 \%$ & $33.3 \%$ & $26.7 \%$ \\
\hline Paper survey & $13,3 \%$ & $20.0 \%$ & $66.7 \%$ \\
\hline Telephone survey & $6.7 \%$ & $26.7 \%$ & $66.7 \%$ \\
\hline HFA/AS participants & & & \\
\hline Face-to-face interview & & & $5.0 \%$ \\
\hline Focus group & $76.7 \%$ & $18.3 \%$ & $9.8 \%$ \\
\hline Online survey & $68.9 \%$ & $21.3 \%$ & $8.2 \%$ \\
\hline Paper survey & $70.5 \%$ & $21.3 \%$ & $23.0 \%$ \\
\hline Telephone interview & $45.9 \%$ & $31.1 \%$ & $26.2 \%$ \\
\hline Telephone survey & $32.8 \%$ & $41.0 \%$ & $45.9 \%$ \\
\hline Carer participants & $26.2 \%$ & $27.9 \%$ & \\
\hline Face-to-face interview & & & $5.9 \%$ \\
\hline Focus group & $76.5 \%$ & $17.6 \%$ & $0.0 \%$ \\
\hline Online survey & $76.5 \%$ & $23.5 \%$ & $29.4 \%$ \\
\hline Paper survey & $64.7 \%$ & $5.9 \%$ & $35.3 \%$ \\
\hline Telephone interview & $52.9 \%$ & $35.3 \%$ & $47.1 \%$ \\
\hline Telephone survey & $58.8 \%$ & $5.9 \%$ & \\
\hline & $52.9 \%$ & $0.0 \%$ & \\
\hline
\end{tabular}

